\title{
Similarities between Complexities in Automotive Manufacturing and Software Development
}

\author{
Tasneem Mirza \\ Research Scholar \\ Thadomal Shahani Engineering College \\ University of Mumbai
}

\author{
Archana Patankar, PhD \\ Professor \\ Thadomal Shahani Engineering College \\ University of Mumbai
}

\begin{abstract}
The Automotive industry is historically a very traditional industry that majorly focuses on mass production of vehicles and selling them. But from over a decade there are major advancements in this sector. Use of technologies like Big data and machine learning has resulted in rapid innovations in this sector. Hence the face of the global automotive manufacturing industry is growing, and with that growth comes the need for evolution and change. Software engineering was suggested in the 1960s to overcome the software crisis. Software crisis was related to the difficulties in developing large complex systems. Software engineering deals with the adoption of an engineering approach to the development of the software that reduces cost of software development leading to a more reliable software. Software engineering is comparatively a newer field as compared to automotive manufacturing. This paper highlights the similarities between the complexities of software development and automotive manufacturing and outlines what manufacturing can learn from software engineering.
\end{abstract}

\section{Keywords}

Software Engineering, Automotive, Agile

\section{INTRODUCTION}

Manufacturing industry has undergone a major change in the last century. There has been an industrial revolution in the field of manufacturing from Industry 1.0 to Industry 4.0. In the era of Industry 1.0 production was made possible using water and steam power. Industry 2.0 saw mass production with the help of electric power. In the last couple of decades of the 20th century, manufacturing of electronic devices like transistors and ICs made it possible to automate individual machines to replace operators i.e. Industry 3.0[1]. In the $21 \mathrm{st}$ century Industry 4.0 is the norm which is bringing IT into manufacturing i.e. smart factories using IOT, big data, cloud computing etc. [2]. Development of software is one of the most important technologies of the world today. Today software is used in almost all major industries of the world including science, business, engineering, medical, transportation, telecommunication, banking etc. Software engineering is a much younger domain as compared to the automotive industry. Software engineering is a discipline which enforces the use of sound engineering principles for the development of software [3]. Software engineering covers not only the technical aspects of building software systems, but also management issues, such as directing programming teams, scheduling, and budgeting etc.

As there is an industrial revolution in manufacturing so there is a revolution in software development. Today innovations in software technology like cloud platform, data analytics, social media etc is changing the way software is developed. Hence software revolution resembles the industrial revolution.
Of all the manufacturing industries, the automotive industry has made a considerable growth. Today, automotive buyers want their vehicles to be equipped with all of the latest technologies. Customers are demanding state-of-the-art cars that ensure a safe, comfortable and luxurious driving experience. Cars are becoming smarter, more connected and easier to use. Customers no longer accept standardized products, but want products that satisfy their individual requirements. Also automotive manufacturers are facing tough competition from its competitors to offer the latest technologies to its customers in minimum possible time. Automotive manufacturers and suppliers are confronted with increasing complexity as a result of increasing numbers of products and options, shorter technology cycles and increasing pressure to innovate [4].

\section{ATTRIBUTES CONTRIBUTING TO THE SIMILARITIES BETWEEN COMPLEXITIES IN SOFTWARE DEVELOPMENT AND AUTOMOTIVE MANUFACTURING}

The following section highlights the attributes contributing to the similarities between software development and automotive manufacturing

\subsection{Globalization Leading To Extremely High Competition}

There is a competitive wave in software development and also in automotive manufacturing.

\section{Software development}

If a person is having a business in the software industry and has great ideas of developing a software that nobody has thought of, there are good chances that another company might have already thought of the same idea. Time to market is also an important criterion in the software industry as result of the stiff completion. Competition can be local or global and can impact the software companies with respect to pricing, reaching out to customers and many other factors [5].

\section{Automotive Industry}

Automotive industry is also facing currently facing a wave of innovation. The automotive industry is in a race as to which company can deliver the latest innovation. Hence there is a stiff competition among its competitors as to who can give the latest innovation in the shortest possible time. Innovations can range from fuel efficient cars, connected cars, in-car infotainment to self-driving cars [6]. 


\subsection{Changing customer requirements or customer involvement}

\section{Software development}

One of the major complexities of any software development is the changing customer needs. The modern world is changing very rapidly and with the change the customer requirements keep changing. One of the major reasons that software projects failed were unclear or changing requirements [7].

\section{Automotive Industry}

For the young generation today a car isn't just a way to travel from one place to another. For them it is a status symbol and a piece of luxury with the car being integrated with the latest gadgets. Today the customer expectations are manifold and keep changing with time. Customers today expect a seamless end to end experience when selecting, purchasing and owning a car. What automakers need is to transform their businesses to ensure that they provide the right customer experience [8].

\subsection{React quickly to changing customer needs}

\section{Software development}

Development of software is a complex process that requires systematic planning and execution to meet the development goals. Many a times the software developer has to react quickly to meet the ever changing customer demands to stay in competition and deliver value to customer faster.

\section{Automotive Industry}

Volatility is the new norm in the automotive industry. If automakers continue to do whatever they did, it won't work for them. As customer demands are changing for example the trend towards the use of electric cars and connected cars, electronics has replaced mechanical engineering. With customers getting accustomed to swift upgrades and latest technology trends in the automotive industry, automakers need to develop different skills to combat the trends and bring in talent with digital expertise quickly to adapt to the industry changes [9].

Software engineering is a discipline which helps the software development process to overcome these complexities using sound engineering principles. Considering the automotive industry, the challenge the OEM's (Original Equipment Manufacturers) face is to remain competitive in this turbulent and volatile market and whether they have the expertise and tools in place to respond to these changes. The answer is that they can, but to manage the complexity in car production, a new mindset has to be developed and new production concepts have to be introduced. As more and more smarter vehicles hit the roads, car companies must simplify vehicle development processes and shorten development cycles by prototyping in more agile and efficient ways [10]

\section{AGILE MODEL IN AUTOMOTIVE INDUSTRY}

One model which is heavily used in the software industry is the agile model which would help to overcome the challenges faced by the OEMs today.

The idea of agile which began in manufacturing in the early 1990 s, took hold in software, not manufacturing. It was software developers who showed the world how a firm could become agile [10].Agile is a mindset and a different way of thinking. In software engineering, agile software development consists of a set of management practices and values centered around the customer and it uses incremental development. It focuses on the collaboration between cross functional and self organizing teams to come up with the solution to the problem domain. Since more than a decade the software industry is taking the advantage of agile principles and concepts. The question is applicability of agile in manufacturing. Due to the technological innovations there are major changes in the automotive market. As a result of these innovations customers are becoming increasingly demanding and there are frequent modifications in the product design. Hence agile can be an answer to deal with volatility in the market [11].

Agile in manufacturing can be applied to areas like project management, product development and supply chain.

Fig. 1 shows the areas where agile can be applied to manufacturing [12]

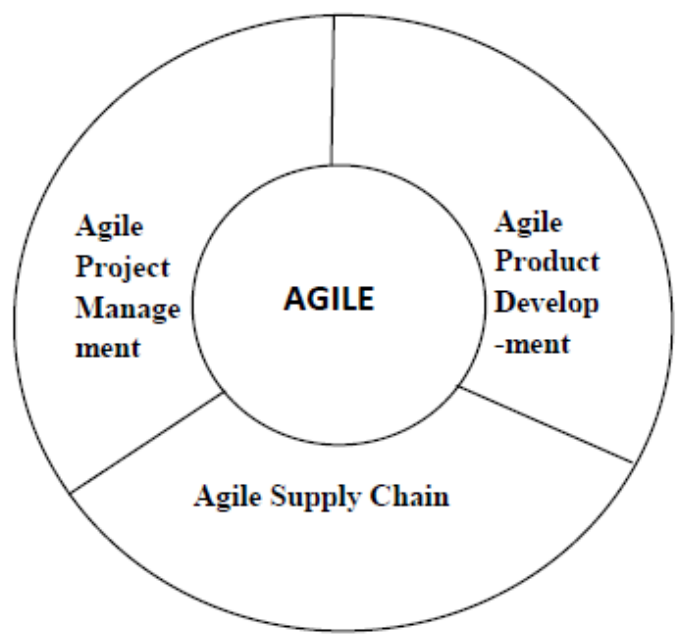

Fig 1: Agile in Automotive Manufacturing

\subsection{Agile Project Management}

When industries are involved in new product development and new technologies, project planning and control can be very challenging. Traditional project management practices are suited for those projects where requirements are crisply defined and rate of changing requirement is very less.

Agile project management in contrast deals with the following features.

1. Unpredictable and changing customer requests.

2. There is a constant and close collaboration with the customer.

3. Documentation is lacking.

4. Iterative project plan.

5. There is a focus on self organizing and cross functional teams

The project is split up into iterations where each iteration lasts from 1 to 4 weeks. The functions are prioritized where the most important ones are taken up at the start and the least are considered at the end. The plan for each iteration is made by the project team. Daily stand up meetings are held where updates about his/her progress is given by each developer [13].

Though agile project management is very popular in the domain of software development there is a reluctance to apply 
the concepts in the non IT sector since frequent changes might be too expensive.

\subsection{Agile Product Development}

Agile product development deals with activities associated with building a product e.g. an automotive product. In the context of automotive manufacturing when applying agile, the cost of change should be very low. Hence for agile product development to be successful in hardware, $3 \mathrm{D}$ printing technologies can be used to boost the agile values. In the absence of $3 \mathrm{D}$ printing technology, fabricating a component using traditional machining could prove to be costly and time consuming when a short agile iteration is applied. Use of $3 \mathrm{D}$ printers have changed the face of the production stage of the automotive industry from prototyping to development of automotive parts [14].

\subsection{Agile Supply chain}

The players in the automotive industry are the OEMs, Tier1 supplier, Tier2 supplier etc. The real strength of the OEMs is marketing, ordering parts from suppliers and final assembly. For most OEMs only $30-35 \%$ of the product is created in house and the rest is outsourced [15][16]. Companies that supply parts to OEMs are called as Tier1 suppliers. Tiers1 suppliers obtain their parts from Tier2. Tier3 supply raw material to Tier2. A car typically contains 20,000 components. Tier1, Tier2 and Tier3 suppliers form a part of the complex automotive supply chain which also includes a number of dealers. To add to this complexity, customers nowadays demand for certain features and specifications which require a quick response from the supply chain. To overcome the complexity in the automotive supply chain, the supply chain should be made agile. Agile supply chain is the necessity to succeed for any organization today to respond to the market volatility. Agile supply chain is an approach to make an organization's supply chain flexible to keep in synchronization with the customer demands.

To make a supply chain agile it should have the following characteristics [17]

1. Virtual Integration: Sharing of real market information originating from the customer to all members in the supply chain.

2. Market Sensitivity: Past trends used to forecast the market demand is an old way to sense the market. Market sensitivity uses the best techniques to forecast the future demand based on the daily point of sale.

3. Process Alignment: Deals with having a trust based relationship between the suppliers and buyers.

4. Network based: Deals with having co-ordination and structure within all members of the supply chain. The entire supply chain should be considered as a single entity to respond to the consumer demand.

\section{EXPERIMENTAL ANALYSIS}

The survey data was collected from different automotive companies like Mahindra, Toyota, Honda, Volkswagen, Nexa. The respondents included employees from different designations ranging from team members to project managers with varied levels of experience and different educational qualifications. Out of the 20 respondents considered more than $50 \%$ of the respondents were of the opinion that there was a high level of technical innovation in the automotive industry which resulted in the market being extremely competitive adding to the complexity and also more than 50 $\%$ of the respondents were of the opinion that the customer requirements keep changing frequently which is challenging for the automotive industry.

\section{CONCLUSION}

The face of the automotive industry is buzzing with innovations. There are innovations in the field of software development too. The paper highlighted the similarities between the complexities in software development and automotive manufacturing in terms of high competition, changing customer requirements and the need to react quickly to the changing customer needs. Software engineering is a discipline when applied to software development leads to overcoming these complexities in software development. The idea is to overcome the complexities and shorten the product development lifecycle in automotive manufacturing by applying software engineering principles i.e. agile model in this case. Agile as a framework with respect to automotive industry can be applied to project management, product development and supply chain management.

\section{ACKNOWLWDGEMENTS}

We gratefully acknowledge the contribution of Dr. G.T. Thampi towards the development of this research paper.

\section{REFERENCES}

[1] https://www.simio.com/blog/2018/09/05/evolutionindustrial-ages-industry-1-0-4-0/ [Last Accessed 05/01/20]

[2] Industry 4.0 Making your business more competitive (White Paper)

[3] Prof P.L.Ramteke, Dr.Mohammad Atique," Software Engineering Challenges: A Case Study”,, Proceedings of the 4th National Conference; INDIACom-2010

[4] Steven Peters, Gisela Lanza, Jun Ni, Jin Xiaoning, Yi Pei-Yun and Marcello Colledani, "Automotive manufacturing technologies - an international viewpoint”, Manufacturing Rev. Volume 1, 2014

[5] https://www.bcg.com/publications/2014/hardware software_human_resources_code_wars_all_industry_ competition_software_talent.aspx $\quad$ [Last Accessed $10 / 01 / 20]$

[6] Saeed Asadi Bagloee, Mohsen Asadi, Tracey Oliver, Madjid Tavana, "Autonomous vehicles: challenges, opportunities, and future implications for transportation policies", Journal of modern transportation, December 2016, Volume 24, Issue 4, pp 284-303.

[7] Deepti Mishra, Alok Mishra,"Complex software project development: agile methods adoption", Journal Of Software Maintenance And Evolution: Research And Practice, J. Softw. Maint. Evol.: Res. Pract. (2011)

[8] https://www.sitel.com/blog/customers-driving-change-inthe-automotive-industry/.[Last Accessed 10/01/20]

[9] https://www.kornferry.com/institute/accelerating-changeautomotive-leadership-wake-call [Last Accessed $15 / 01 / 20]$

[10] https://www.forbes.com/sites/stevedenning /2012/09/24/how-manufacturing-can-learn-from- 
software- to-become-agile/\#52107466bd6b [Last Accessed 11/12/2017]

[11] Milos Jovanovic, Bojan Lalic, Antònia Mas,Antoni Lluís Mesquida,"The Agile approach in industrial and software engineering project management", Journal of Applied Engineering Science 13(2015)4,331

[12] Tasneem Mirza, Dr. Archana Patankar,"Agile in Automotive Manufacturing", IOSR Journal of Computer Engineering (IOSR-JCE) e-ISSN: 2278-0661,p-ISSN: 2278-8727, PP 01-04

[13] Aljaž Stare,"Agile Project Management in Product Development Projects", Procedia-Social and Behaviorial Sciences 119(2014)295-304.
[14] http://www.divbyz.com/industries/automotive [Last Accessed 23/12/2017]

[15] Intaher M. Ambe, Johanna A. Badenhorst-Weiss," An Automotive Supply Chain Model For a Demand-Driven Environment", Journal of Transport and Supply Chain Management; Vol 5, No 1 (2011), 1-22. doi: $10.4102 /$ jtscm.v5i1.18

[16] Ambe, I. M., Badenhorst-Weiss, J. A. , "Strategic supply chain framework for the automotive Industry". African Journal of Business Management Vol. 4(10), pp. 2110- 2120, 18August, 2010.

[17] Intaher Marcus AMBE,"Agile Supply Chain: Strategy for competitive Advantage", Journal of Global Strategic Management V. 4, N 1, 2010-June 